\title{
PARTICIPAC̣ÃO dA RADIOLOGIA NAS PERÍCIAS NECROSCÓPICAS DE BALEADOS REALIZADAS NO INSTITUTO MÉDICO-LEGAL DO RIO DE JANEIRO*
}

\author{
Silvia Falcão de Oliveira ${ }^{1}$, Hilton Augusto Koch ${ }^{2}$, Casimiro Abreu Possante de Almeida ${ }^{3}$, \\ Bianca Gutfilen ${ }^{4}$
}

Resumo OBJETIVO: Este trabalho aborda as conseqüências de laudos necroscópicos incompletos de baleados, nos casos em que não foi possível o uso de recursos radiológicos para localizar os projéteis de arma de fogo. MATERIAIS E MÉTODOS: Foram analisados 8.185 laudos necroscópicos do Instituto Médico-Legal Afrânio Peixoto, Rio de Janeiro, RJ, referentes à demanda total de cadáveres no período de 10 de janeiro a 31 de dezembro de 2001, dos quais 3.122 casos corresponderam a necropsias de baleados. RESULTADOS: Desses casos, 309 corpos foram sepultados contendo ainda, no seu interior, projéteis de arma de fogo, podendo suscitar futuras indagações judiciais. No mesmo período foram solicitadas 23 exumações, 12 delas com a finalidade de recolher projéteis. Foram calculados os gastos relacionados à realização de necropsias de baleados - R\$996,85 - e custos alusivos à realização de exumações com a finalidade de recolher projéteis de arma de fogo - R\$ 1.155,40, visando a estabelecer o montante financeiro que poderia ser poupado pelos cofres públicos, a ser alocado para finalidades outras, se a perícia médico-legal de baleados, no exame inicial, obtivesse sucesso. CONCLUSÃO: Os resultados permitiram concluir que todos os atos necroscópicos de baleados devem seguir protocolos específicos, uma vez que perícias incompletas exigem exumação posterior, com gastos adicionais desnecessários.

Unitermos: Radiologia; Medicina legal; Radioscopia; Necropsia; Projéteis de arma de fogo.

\begin{abstract}
The role of radiology in autopsy in gunshot wounds cases performed at "Instituto Médico Legal" of Rio de Janeiro.

OBJECTIVE: To evaluate the consequences of incomplete necropsy reports of gunshot victims, in cases in which radiological methods were not used to locate the firearm projectiles. MATERIALS AND METHODS: A total of 8,185 necropsy reports of "Instituto Médico-Legal Afrânio Peixoto", Rio de Janeiro, Brazil, were reviewed. This corresponds to the total number of corpses of the period from January to December 2001, and 3,122 of these consisted of autopsies of gunshot victims. RESULTS: Out of these 3,122, 309 bodies were buried with the firearm projectiles in its interior, which may lead to legal investigations in the future. In the same period 23 exhumations were requested, 12 of them with the purpose of collecting projectiles. The expenses related to the performance of necropsy exams of gunshot victims were calculated in about U\$ 344 whereas the expenses related to the exhumations for the purpose of collecting firearm projectiles were calculated in about $\mathrm{U} \$ 399$. These calculations were performed to show the total amount that could be saved and otherwise spent, if legal-medical investigations of gunshot victims were successfully performed at first examination. In conclusion, necropsy examinations of gunshot victims must follow specific protocols, since incomplete necropsies will require posterior exhumations, with unnecessary additional costs. Key words: Radiology; Forensic Medicine; Radioscopy; Necropsy; Bullets.
\end{abstract}

* Trabalho realizado no Instituto Médico-Legal Afrânio Peixoto, Rio de Janeiro, RJ.

1. Perita-legista do Instituto Médico-Legal Afrânio Peixoto, Mestranda do Departamento de Radiologia da Universidade Federal do Rio de Janeiro (UFRJ).

2. Professor Titular do Departamento de Radiologia da Faculdade de Medicina da UFRJ.

3. Professor Adjunto da Faculdade de Odontologia da UFRJ.

4. Professora Adjunta do Departamento de Radiologia da Faculdade de Medicina da UFRJ.

Endereço para correspondência. Profa. Dra. Bianca Gutfilen. Universidade Federal do Rio de Janeiro, Departamento de Radiologia, Hospital Universitário Clementino Fraga Filho. Avenida Brigadeiro Trompovsky, s/no, Ilha do Fundão. Rio de Janeiro, RJ, 21941-590. E-mail: bgutfilen@hucff.ufrj.br

Recebido para publicação em 24/6/2004. Aceito, após revisão, em 13/8/2004.

\section{INTRODUÇÃO}

Quando a perícia necroscópica diz respeito a exames de indivíduos baleados, é fundamental o encontro e a arrecadação dos projéteis de arma de fogo. Ocorre que, quando um projétil é deflagrado, em sua estrutura ficam imprimidas ranhuras, adquiridas durante a passagem pelo cano da arma. Se o conjunto das estrias existentes no projétil recolhido de um cadáver, quando confrontado, for igual ao conjunto existente em um projétil disparado por uma arma conhecida, a perícia criminal estará habilitada a afirmar que o projétil suspeito saiu daquele cano em estudo, constituindo essa a base da perícia de projéteis de arma de fogo ${ }^{(1)}$.

Se o corpo a ser necropsiado corresponde à vítima de projétil único, a observação da ferida de entrada do projétil permite, eventualmente, que se estabeleça o trajeto percorrido no interior do corpo, pela sua relação com a ferida de saída. Mas, quando se trata de ferimento penetrante, e não transfixante do corpo, mesmo um disparo único pode causar transtornos na condução da perícia, notada- 
mente se o projétil fizer um trajeto bizarro e localizar-se em sítio de difícil acesso. Em tal situação, ainda que o técnico de necropsias seja bastante experiente, o êxito da perícia só se dará através da radios$\operatorname{copia}^{(2-4)}$.

A demanda de exames radiológicos no Instituto Médico-Legal Afrânio Peixoto (IMLAP)-Sede revela estatística crescente a cada ano, sem que tenha ocorrido a adequação das instalações e equipamentos destinados a tal mister, bem como o aumento de recursos humanos e o indispensável investimento na sua formação específica. Surgem, assim, lacunas no atendimento, que levam a consideráveis prejuízos nas demandas periciais.

Os exames necroscópicos, de forma rotineira, são efetuados no período diurno, das 9h00 às 21h00, quando ainda são possíveis recursos técnicos fundamentais, tais como a radioscopia.

As necropsias de exceção, realizadas no período noturno por determinação de autoridades, ou aquelas realizadas em horários outros, carentes de técnicos de raios$\mathrm{X}(\mathrm{RX})$ ou de aparelhagem em condições de uso, correm o risco de ficarem incompletas, pelos motivos já expostos.

O presente trabalho aborda a participação da Radiologia nos exames necroscópicos, analisando as conseqüências decorrentes de perícias inadequadas em função de carências de recursos radiológicos, com especial enfoque nas perdas financeiras.

\section{MATERIAIS E MÉTODOS}

Inicialmente foi feito o levantamento quantitativo de todas as necropsias realizadas no IMLAP, de $1^{\circ}$ de janeiro a 31 de dezembro de 2001. Dentre aqueles exames foram selecionados, de acordo com o critério de inclusão estabelecido, os correspondentes aos cadáveres de baleados, destacando-se os que apresentavam justificativas pelo não recolhimento de eventuais projéteis de arma de fogo. As demais causas de morte violenta, ou aquelas decorrentes de causas naturais estabelecidas através da simples verificação de óbito, participaram como critério de exclusão, incluindo assim as mortes decorrentes de ação contundente, ação cortante, ação pérfuro-cortante, ação corto-contundente, ação térmi- ca, ação elétrica, asfixias, intoxicações exógenas ou da atuação de outros tipos de energia. Também foram pesquisadas as exumações solicitadas no mesmo período.

$\mathrm{Na}$ fase seguinte, procedeu-se ao cálculo dos custos, aos cofres do Estado, tanto da necropsia de um baleado, como também de uma exumação com a finalidade de arrecadar projéteis de arma de fogo. Considerou-se, para facilitar o cálculo, o período de uma hora de trabalho para cada profissional envolvido, sabendo-se ser esse o lapso de tempo utilizado, em média, para a efetiva atuação das diversas categorias na resolução da perícia.

\section{RESULTADOS}

1. Das amostras - A totalização dos dados apurados na pesquisa apontou 8.185

Quadro 1 Laudos iniciais de projéteis de arma de fogo que originaram exumações.

\begin{tabular}{|c|c|c|c|c|}
\hline & Laudo & $\begin{array}{l}\text { PAF* } \\
\text { recolhido }\end{array}$ & Causa de morte & Justificativa \\
\hline 1 & $5208 / 01$ & Não & $\begin{array}{l}\text { Ferimentos transfixantes } \\
\text { do crânio e pescoço }\end{array}$ & $\begin{array}{l}\text { "Não foi submetido a exame radioscópico por } \\
\text { deficiência da Instituição, que não dispõe de } \\
\text { técnico de raios X no plantão" }\end{array}$ \\
\hline 2 & $5209 / 01$ & Não & $\begin{array}{l}\text { Ferimentos transfixantes } \\
\text { e penetrantes do crânio } \\
\text { e abdome }\end{array}$ & $\begin{array}{l}\text { "Não foi submetido a exame radioscópico por } \\
\text { deficiência da Instituição, que não dispõe de } \\
\text { técnico de raios X no plantão; apesar das } \\
\text { exaustivas buscas, não foi possível encontrar } \\
\text { projétil de arma de fogo" }\end{array}$ \\
\hline 3 & $5210 / 01$ & Dois & $\begin{array}{l}\text { Ferimentos penetrantes } \\
\text { e transfixantes do crânio } \\
\text { e abdome }\end{array}$ & $\begin{array}{l}\text { "Não foi submetido a exame radioscópico por } \\
\text { deficiência da Instituição, que não dispõe de } \\
\text { técnico de raios X no plantão" }\end{array}$ \\
\hline 4 & $5211 / 01$ & Um & $\begin{array}{l}\text { Ferimento transfixante } \\
\text { do crânio }\end{array}$ & $\begin{array}{l}\text { "O corpo não foi submetido a radioscopia por } \\
\text { inoperância de equipamento" }\end{array}$ \\
\hline 5 & $5212 / 01$ & Seis & $\begin{array}{l}\text { Ferimentos transfixantes } \\
\text { do encéfalo, fígado e } \\
\text { aorta abdominal }\end{array}$ & $\begin{array}{l}\text { "Após exaustivas tentativas e por inoperância } \\
\text { de equipamento, não foi possível encontrar } \\
\text { outros prováveis projéteis de arma de fogo" }\end{array}$ \\
\hline 6 & $5213 / 01$ & Não & $\begin{array}{l}\text { Ferimento transfixante } \\
\text { do crânio e abdome }\end{array}$ & $\begin{array}{l}\text { "Não foi submetido a exame radioscópico por } \\
\text { deficiência da Instituição, que não dispõe de } \\
\text { técnico de raios X no plantão" }\end{array}$ \\
\hline 7 & $5214 / 01$ & Um & $\begin{array}{l}\text { Ferimento transfixante } \\
\text { do pulmão direito }\end{array}$ & Sem comentários \\
\hline 8 & $5215 / 01$ & Não & $\begin{array}{l}\text { Ferimento transfixante } \\
\text { do encéfalo }\end{array}$ & $\begin{array}{l}\text { "O cadáver não foi submetido à radioscopia } \\
\text { por inoperância de aparelho" }\end{array}$ \\
\hline 9 & $5216 / 01$ & Não & $\begin{array}{l}\text { Ferimento transfixante } \\
\text { do crânio }\end{array}$ & $\begin{array}{l}\text { "Não foi submetido a exame radioscópico por } \\
\text { deficiência da Instituição, que não dispõe de } \\
\text { técnico de raios X no momento" }\end{array}$ \\
\hline 10 & $5217 / 01$ & Não & $\begin{array}{l}\text { Ferimento transfixante } \\
\text { do crânio }\end{array}$ & $\begin{array}{l}\text { "O corpo não foi submetido à radioscopia por } \\
\text { inoperância do aparelho" }\end{array}$ \\
\hline 11 & $5218 / 01$ & Não & $\begin{array}{l}\text { Ferimentos transfixantes } \\
\text { do pescoço, tórax e ab- } \\
\text { dome }\end{array}$ & $\begin{array}{l}\text { "Não foi submetido a exame radioscópico por } \\
\text { falta de técnico de raios X no plantão; apesar } \\
\text { das exaustivas buscas, não foi possível encon- } \\
\text { trar provável projétil de arma de fogo" }\end{array}$ \\
\hline 12 & $5220 / 01$ & Dois & $\begin{array}{l}\text { Ferimentos transfixantes } \\
\text { do crânio }\end{array}$ & $\begin{array}{l}\text { "Não foi submetido a exame radioscópico por } \\
\text { deficiência da Instituição, que não dispõe de } \\
\text { técnico de raios X no plantão" }\end{array}$ \\
\hline
\end{tabular}

\footnotetext{
* PAF, projétil de arma de fogo.
}

exames necroscópicos realizados no período de um ano, de $1^{\circ}$ de janeiro a 31 de dezembro de 2001, sendo 3.122 (38\%) referentes a corpos de baleados. Entre os 3.122 laudos de baleados, 309 (10\%) deles continham justificativas, feitas pelos peritos relatores, quanto ao não recolhimento de eventuais projéteis de arma de fogo (Quadro 1), caracterizando tais exames como incompletos e, portanto, passíveis de indagações judiciais. Foram solicitadas, no mesmo período, 23 exumações, sendo 12 delas com a finalidade de arrecadar projéteis

2. Dos custos - Os gastos referentes à realização de uma necropsia forense totalizaram $\mathrm{R} \$ 996,85$ (discriminados na Tabela 1). Os gastos referentes à realização de uma exumação totalizaram R \$ 1.155,40 (discriminados na Tabela 2). 
Tabela 1 Totalização dos gastos relacionados à realização de uma necropsia.

\begin{tabular}{|l|l|}
\hline Gastos & Valor (R\$) \\
\hline Funcionários* & 211,70 \\
Material de consumo & 785,15 \\
\hline Total & 996,85 \\
\hline
\end{tabular}

* Consideradas as equipes de local de crime e do IML.

Tabela 2 Totalização dos gastos relacionados à realização de uma exumação.

\begin{tabular}{|l|l|}
\hline Gastos & Valor (R\$) \\
\hline Funcionários no cemitério & 115,70 \\
Material de consumo no cemitério & 151,45 \\
Funcionários do IML & 103,10 \\
Material de consumo no IML & 785,15 \\
\hline Total & $1.155,40$ \\
\hline
\end{tabular}

\section{DISCUSSÃO}

$\mathrm{Na}$ literatura forense universal existe um consenso quanto à necessidade da adoção e da utilização sistemática de recursos radiológicos nas atividades necroscópicas $^{(5-8)}$. Na busca e recuperação de projéteis de arma de fogo são fundamentais aqueles recursos.

No IMLAP, do Rio de Janeiro, a demanda de cadáveres, crescente a cada ano, somada à manutenção descontinuada dos equipamentos radiológicos e ao número insuficiente de técnicos de RX para compor as equipes, tem gerado lacunas na evolução dos trabalhos periciais, principalmente no que tange aos procedimentos necroscópicos.

O levantamento realizado para a confecção deste trabalho apurou 3.122 laudos referentes a cadáveres de baleados, de $1^{\circ} \underline{ }$ de janeiro a 31 de dezembro de 2001. Foi possível concluir que $10 \%$ deles contêm justificativas pelo não recolhimento de projéteis, significando dizer que foram sepultados 309 corpos contendo ainda, no seu interior, eventuais provas de crime. Tais relatórios, inadequados, podem, como conseqüência, gerar a exigência de uma complementação posterior da perícia, somente exeqüível através de exumação.

A leitura cuidadosa dos laudos que deram origem a solicitações de exumações permite observar que em determinados corpos foi possível arrecadar alguns, mas não todos os projéteis; em outros corpos, nenhum projétil foi arrecadado. Ambas as situações são alvo de interesse da Justiça, pois quando um corpo é atingido por vários projéteis, pode ter sido vítima de diversos agentes na prática delituosa, sendo importantes os informes pertinentes à participação de cada projétil, para a obtenção do êxito letal.

A pesquisa apurou que foram solicitadas 23 exumações, sendo 12 delas com a finalidade de arrecadar projéteis. Embora a quantidade apurada aparente ser inexpressiva em relação ao número de laudos incompletos, cumpre ressaltar que as exumações não costumam guardar contemporaneidade com os laudos que lhes dão origem, sendo requisitadas, não raras vezes, alguns anos após a perícia inicial.

As exumações, realizadas para suprir as falhas ocorridas na evolução das perícias, além de promoverem embaraços na tramitação do processo judicial e de levarem sofrimento aos familiares que acompanham as diligências, causam prejuízos financeiros expressivos. De acordo com o levantamento de custos, foi possível demonstrar que os gastos provenientes de uma exumação excedem, em muito, aqueles gerados através de exames necroscópicos comuns, com participação da radioscopia. No ano de 2001 houve um custo adicional de R\$ 13.864,80 aos cofres públicos, calculados a partir do custo de uma exumação - $\mathrm{R} \$$ $1.155,40$ - multiplicado pelo número de necropsias incompletas de baleados -12 . Se fossem computadas não como exumações em potencial, mas como exumações obrigatórias em cumprimento aos trâmites legais, os exames necroscópicos incompletos de baleados, realizados no ano de 2001, correspondentes a 309 laudos, determinariam um gasto adicional de $\mathrm{R} \$$ $357.018,60$, calculados a partir do custo de uma exumação — $\mathrm{R} \$ 1.155,40$ - multiplicado pelo número de necropsias incompletas - 309, ou seja, um gasto desnecessário e perfeitamente evitável se a Radiologia do IMLAP estivesse equipada, com recursos humanos e com material, na medida certa da sua importância no contexto médico-legal.

Assim como ocorre na Medicina, há exigência de diagnósticos precisos e ágeis nos laudos periciais, para o correto atendimento à Justiça, e, para isso, a boa con- duta técnica preconiza que o necropsista busque apoio nas especialidades que compõem o universo pericial, quando necessário. Contudo, com relação à Radiologia, aquele especialista tem-se conformado em desenvolver suas atividades de maneira econômica, em razão das barreiras financeiras existentes no serviço público, que interferem diretamente nos mecanismos operacionais e geram a busca de critérios alternativos de adaptação.

Novas técnicas de imagens, como ressonância magnética e tomografia computadorizada, vêm sendo incorporadas gradualmente à prática forense mundial ${ }^{(\mathbf{9}, 10)}$, embora problemas de custo e acessibilidade precisem ser resolvidos antes que essas técnicas possam começar a participar daquela rotina ${ }^{(11)}$. Já é possível constatar que nos serviços médico-legais de diversos países os avanços da tecnologia contribuem não somente para as perícias necroscópicas, mas também para os exames forenses concernentes à clínica médico-legal $^{(\mathbf{1 2 - 1 4 )}}$. No entanto, no IMLAP, a carência de instrumental e de pessoal impede uma visão mais ampla acerca dos equipamentos modernos que poderiam contribuir para melhorias dos atos periciais, e são almejadas apenas as técnicas mais simples da Radiologia.

Os dados obtidos permitem aos autores estabelecer as seguintes conclusões: 1) a prova pericial tem, na Radiologia, poderosa, confiável e insubstituível aliada, nos casos de cadáveres baleados; 2) todos os atos necroscópicos de baleados devem ser realizados seguindo protocolos específicos; 3 ) uma perícia incompleta em cadáver de baleado promove um gasto adicional de $\mathrm{R} \$ 1.155,40$, correspondente à realização de exumação posterior, para arrecadação de eventuais projéteis de arma de fogo; 4) para que, no Rio de Janeiro, a Justiça seja atendida nas suas necessidades, faz-se imprescindível que, em casos de cadáveres de baleados, o Instituto Médico-Legal conte com os recursos humanos e materiais necessários para a execução plena e segura dos exames radiológicos pertinentes.

\section{Agradecimento}

Ao Instituto Médico-Legal Afrânio Peixoto, Rio de Janeiro, RJ. 


\section{REFERÊNCIAS}

1. Carvalho HV, Segre M, Meira AR, et al. Compêndio de medicina legal. $2^{\mathrm{a}}$ ed. atualizada. São Paulo: Saraiva, 1992

2. Almeida Júnior A. Lições de medicina legal. 22aㅡ ed Rio de Janeiro: Nacional, 1998.

3. Arbenz GO. Medicina legal e antropologia forense. Rio de Janeiro-São Paulo: Livraria Atheneu, 1988.

4. Peixoto A. Medicina legal. 6 ${ }^{\underline{a}}$ ed. Rio de Janeiro Livraria Francisco Alves, 1931.

5. Brogdon BG. The scope of forensic radiology. Clin Lab Med 1998;18:203-40.

6. Eckert WG, Garland N. The history of the forensic applications in radiology. Am J Forensic Med Pathol 1984;5:53-6.
7. Fatteh AV, Mann GT. The role of radiology in forensic pathology. Med Sci Law 1969;9:27-30

8. Rainio J, Lalu K, Ranta H, Penttilä A. Radiology in forensic expert team operations. Leg Med (Tokyo) 2001;3:34-43.

9. Thali MJ, Yen K, Schweitzer W, et al. Virtopsy, a new imaging horizon in forensic pathology: virtual autopsy by postmortem multislice computed tomography (MSCT) and magnetic resonance imaging (MRI) - a feasibility study. J Forensic Sci 2003;48:386-403.

10. Thali MJ, Schweitzer W, Yen K, et al. New horizons in forensic radiology: the 60-second digital autopsy-full-body examination of a gunshot victim by multislice computed tomography. Am J Forensic Med Pathol 2003;24:22-7.
11. Newman J, McLemore J. Forensic medicine: matters of life and death. Radiol Technol 1999;71: 169-85; quiz 186-8, 191.

12. Scialpi M, Boccuzzi F, Romeo F, et al. Computerized tomography in craniocerebral, maxillofacial, cervical, and spinal gunshot wounds. Part II -Clinical contribution and medico-legal aspects. Radiol Med (Torino) 1996;92:693-9.

13. Schyma C, Bittner M, Placidi P. The men frangible: study of a new bullet in gelatin. Am J Forensic Med Pathol 1997;18:325-30.

14. Stein KM, Bahner ML, Merkel J, Ain S, Mattern R Detection of gunshot residues in routine CTs. Int J Legal Med 2000;114:15-8. 